\title{
Isolation and characterization of the subacute spongiform virus encephalopathies of man: kuru and Creutzfeldt-Jakob disease
}

\author{
CLARENCE J. GIBBS JR AND D. CARLETON GAJDUSEK
}

From the National Institutes of Health, Bethesda, Maryland, USA

Kuru, a chronic subacute heredofamilial disease of man in the eastern highlands of New Guinea, and Creutzfeldt-Jakob disease, one of the presenile dementias which occurs sporadically and in familial patterns in man throughout the world, are caused by infectious agents which are experimentally transmissible from man to chimpanzees and several species of monkeys (Gajdusek, Gibbs, and Alpers, 1966; Gibbs, Gajdusek, Asher, Alpers, Beck, Daniel, and Matthews, 1968; Gajdusek, Gibbs, Asher, and David, 1968; Gajdusek and Gibbs, 1971). Both kuru and Creutzfeldt-Jakob disease are associated with long, asymptomatic incubation periods of from several months to several years. Although they have infection as their aetiology neither disease manifests the cardinal signs associated with acute viral infections. There is no cerebrospinal fluid pleocytosis or significant elevated proteins, haematological values and clinical chemistry findings are within normal limits, and there is no febrileresponse at any stage of disease. Both diseases always terminate in death of the patient or experimentally affected animal following a clinical course of ataxia, incoordination, disturbed gait, titubation, myoclonus, fasciculations, and wasting lassitude. Histopathological lesions are restricted to the central nervous system, primarily the grey matter of the brain, and consist of neuronal vacuolation and dropout, astrocytic hypertrophy and proliferation, and varying degrees of intracellular status spongiosis. In addition, in the primary disease in man PASpositive, doubly refractive birefringent amyloid plaques and a loss of Purkinje cells are observed in the brain. Evidence of inflammatory reaction is either totally lacking or only minimally present.

However, these clinical and histopathological findings are not entirely specific for kuru and Creutzfeldt-Jakob disease but are also characteristic for two animal diseases, scrapie of sheep and mink encephalopathy. Both animal diseases, like their human counterparts, are transmissible to a wide variety of experimental hosts. Because of the striking similarities clinically and histologically between these four diseases-kuru, Creutzfeldt-Jakob disease, scrapie, and mink encephalopathy-we have designated them the prototype viruses of a new group of infectious agents which we have called the subacute spongiform encephalopathies.

Such virus-induced spongiform encephalopathies can no longer be looked upon as medical exotica (Asher, Gajdusek, and Gibbs, 1971). They are transmissible diseases which present actual problems of concern to neurologists, neuropathologists, gerontologists, and infectionists as well as to virologists. Indeed, as Dr Gajdusek has already pointed out in the preceding paper, during the past seven years since kuru has been transmitted, it has become increasingly evident that there are many human patients dying with presenile degenerative diseases of the brain which are difficult to classify but which may well be 'slow infections' of virus aetiology. Such subacute and chronic inflammatory diseases of the brain may also result from persistent viral infections. Examples are subacute sclerosing panencephalitis associated with a persistent measles virus infection (Baublis and Payne, 1968); progressive multifocal leucoencephalopathy associated with $\mathbf{S V}_{40}$-like papova virus; and epilepsy partialis continua with associated viral inclusion bodies thought to be caused by aberrant inflammatory responses to persistent viral infections. Finally, another disease in which virus-like particles have been seen but whose significance remains unclear is cystic muscle lesions of polymyositis. Such reports include EM detection of myxovirus-like particles (Chou, 1967, 1968; Carpenter, Karpati, and Wolfe, 1970) and of picorna virus-like particles (Chou and Gutman, 1970). Todate, however, it remains unclear whether these viruses play any part in the aetiology of the diseases with which they are associated or whether they simply fill favourable niches in tissues altered by diseases which have other primary causes (Gajdusek and Gibbs, 1971).

The purpose of this paper is to present data on the 

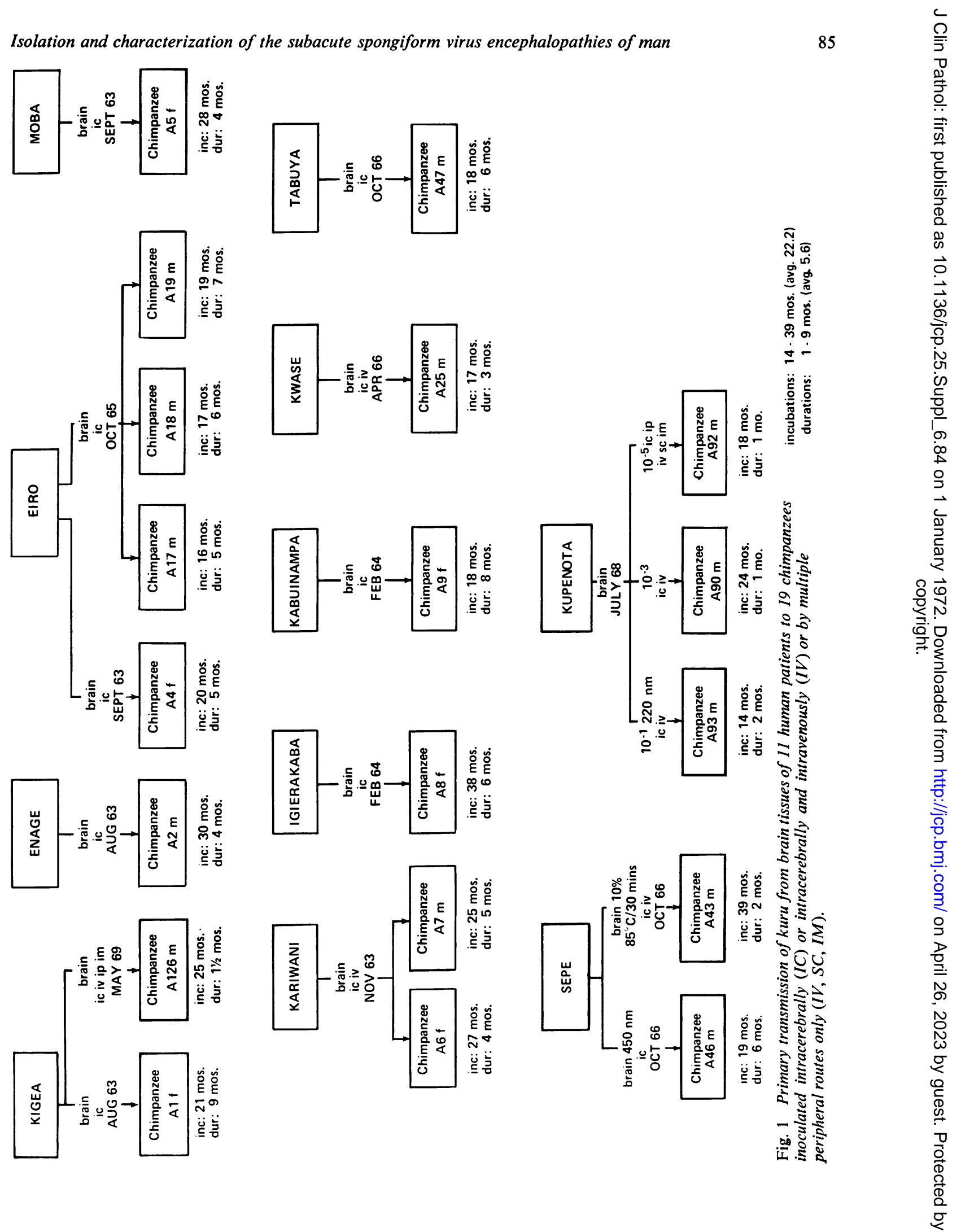
isolation and characterization of the atypical viruses of kuru and Creutzfeldt-Jakob disease - two of the prototype subacute spongiform virus encephalopathies. The techniques employed in these studies have been previously reported in detail (Gibbs and Gajdusek, 1965) and have not undergone any significant change.

\section{Kuru}

Kuru is an invariably fatal degenerative disease of the central nervous system, characterized by cerebellar ataxia and trembling, progressive dysarthria and, finally, dysphagia, which has been observed only in the Fore people and their neighbours who reside in a restricted part of the Eastern Highlands of New Guinea (Gajdusek and Zigas, 1957; Gajdusek, 1963). The disease is caused by a filterable agent and is transmissible from humans to chimpanzees, from chimpanzees to chimpanzees (Gajdusek et al, 1966; Gajdusek, 1967; Gibbs, Alpers, and Gajdusek, 1969; Gibbs and Gajdusek, 1970). Further, the disease has been transmitted from humans to a rhesus monkey (Gajdusek and Gibbs, in press) and five species of new-world monkeys. Similar transmissions of the virus have been made to new-world monkeys inoculated with tissues from affected chimpanzees (Gajdusek et al, 1968; Gajdusek and Gibbs, 1971; Gibbs, 1971). The disease has now been transmitted from 11 human patients to 18 chimpanzees with incubation periods varying from 14 to 39 months (Fig. 1) and in five serial passages from chimpanzee to chimpanzee with incubation periods of 10 to 18 months (Fig. 2). The mean incubation period has thus dropped on chimpanzee-to-chimpanzee passage from 22 to 11 months. Primary and serial trans-

CMIMPANIEE

I

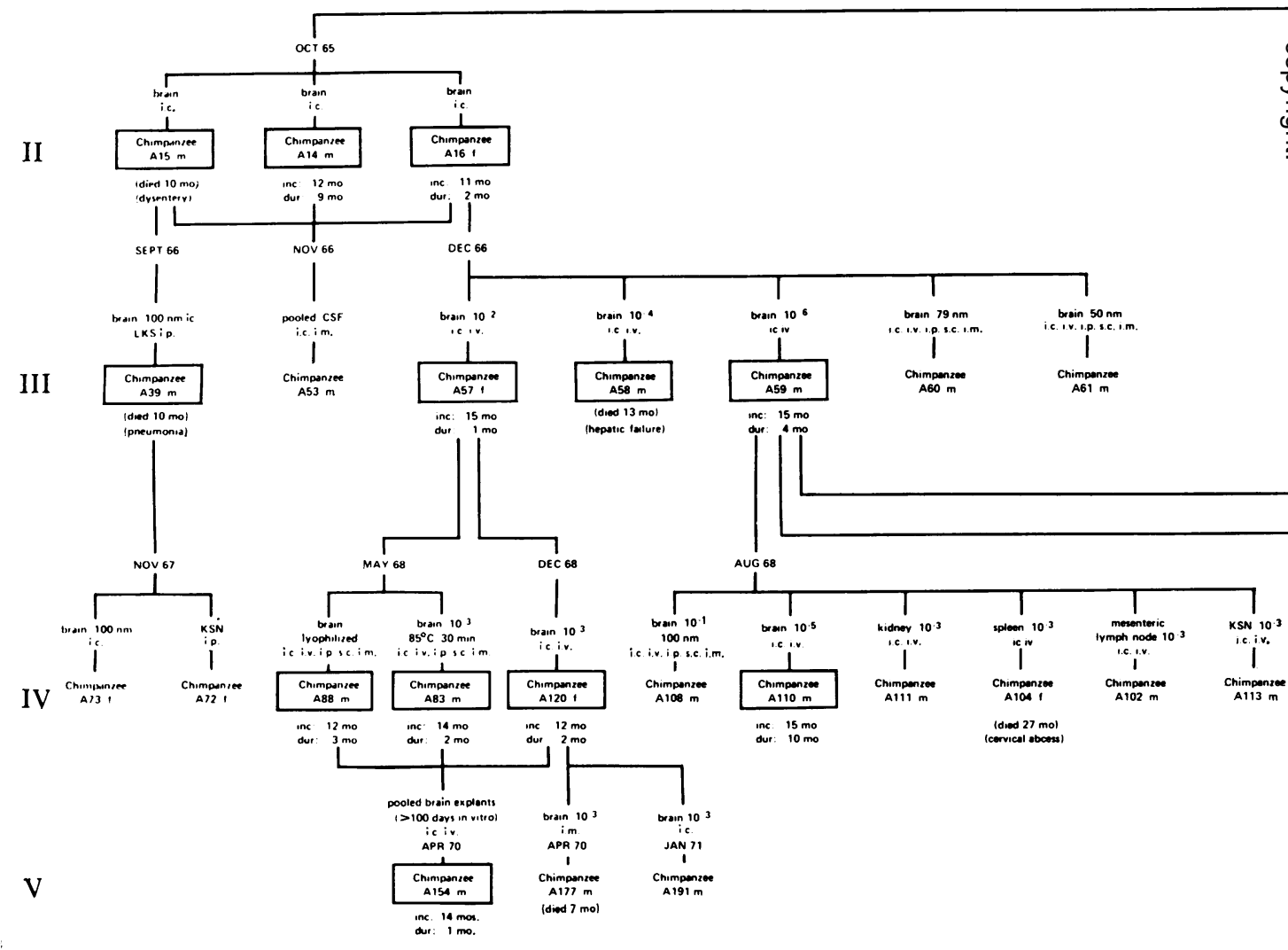


missions are successfully accomplished in animals inoculated intracerebrally (IC), intracerebrally and intravenously (IV), or by multiple peripheral routes (IV, SC, IM) only. In addition to the chimpanzee, kuru has also been transmitted directly from human brain to the rhesus monkey after an incubation period of eight years and five months (Gajdusek and Gibbs, 1972). Primary transmissions have also been made to five species of new-world monkeys-the spider (Ateles geoffroyi), the capuchin (Cebe sapella and Cebes albifrons), the squirrel (Saimiri sciureus), with a much longer mean incubation of 30 months and with a range of 20 to 51 months (Figs. 3, 4, and 5), and the
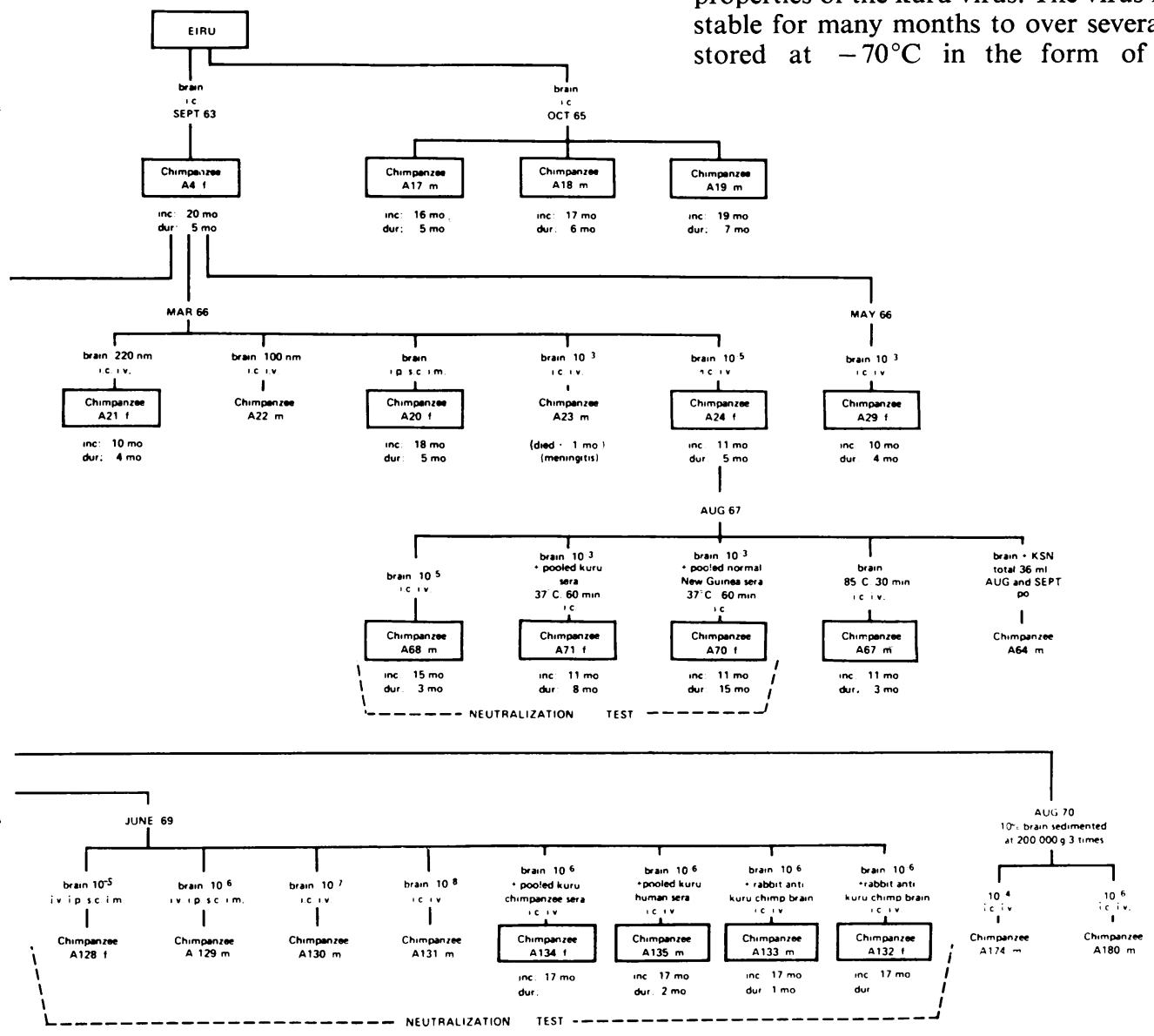

Fig. 2 Summary of five serial passages of kuru virus, Eiru (Eiro) strain, in chimpanzees, and data on the physical, biological, and immunological properties of the virus. woolly monkey. In serial passage kuru has been transmitted from chimpanzees to new-world monkeys and from new-world monkeys to new-world monkeys (Figs. 4 and 5). In serial passage in newworld monkeys the incubation periods had not appreciably dropped until recently (Fig. 5) when a second passage level virus in capuchin monkeys has been causing disease in 10 to 12 months. Obviously, much of our investigation of kuru is now done with this strain in this species of monkey.

In addition to data on primary transmission and serial passages in chimpanzees, Figure 6 and Figure 2, respectively, also contain information on some of the properties of the kuru virus. The virus is remarkably stable for many months to over several years when stored at $-70^{\circ} \mathrm{C}$ in the form of brain tissue 


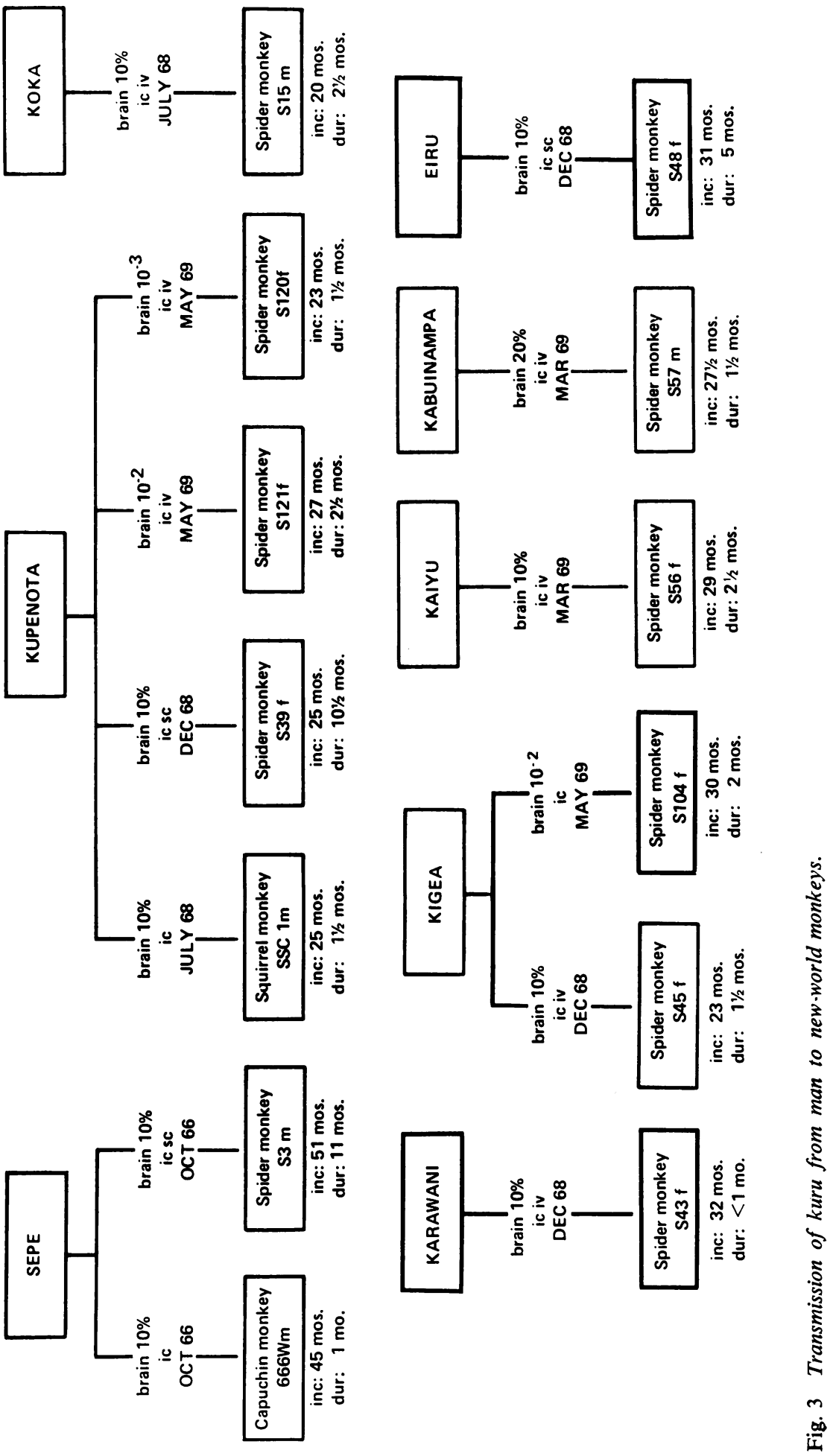

율 


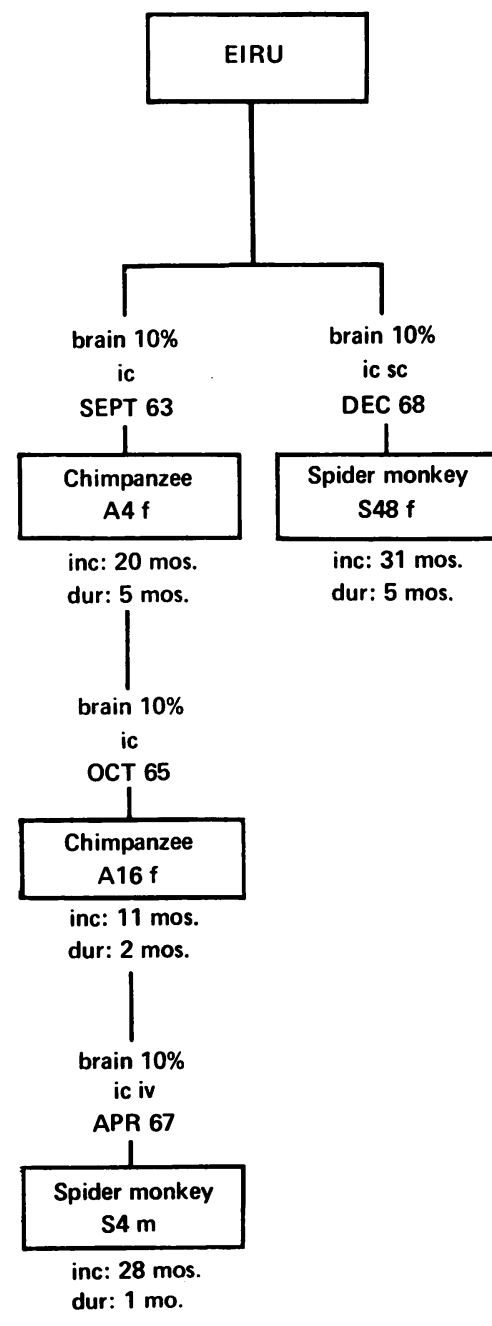

Fig. 4 Eiru strain of kuru in new-world monkeys.

suspensions prepared in phosphate-buffered saline. In comparison to most conventional viruses, kuru virus is very thermostable and infectivity is not destroyed or appreciably reduced following exposure of the virus to a temperature of $85^{\circ} \mathrm{C}$ for 30 minutes. Human brain tissue contains more than $10^{6}$ infectious doses of virus per $\mathrm{ml}$ of suspension (Fig. 6); for the infected chimpanzee brain infectivity titre endpoints exceed $10^{7.5}$ infectious doses per $\mathrm{ml}$ (Fig. 2) and spider monkey brain infectivity titres exceed $10^{6}$ infectious doses per $\mathrm{ml}$. The virus passes through a $220 \mathrm{~nm}$ Millipore filter but has not yet been detected in the filtrates of $100 \mathrm{~nm}$ or smaller Millipore filters. Virus has not been recovered from whole blood or serum or from urine, cerebrospinal fluid, milk, placenta, or amniotic fluids of kuru patients (Fig. 7) or experimental animals. However, the disease has been transmitted to chimpanzees inoculated with small amounts of pooled suspensions of liver, kidney, spleen, and mesenteric lymph node from chimpanzees killed in the terminal stage of the disease (Fig. 8). As shown, the disease can also be serially transmitted in chimpanzees peripherally only without the need of assaulting the brain to induce disease. Experiments have already been initiated to determine the efficacy of transmissions by single routes of inoculations, including intradermal, conjunctival, and intranasal, as well as to find whether or not this will influence the incubation periods or course of the disease. In recent experiments, Field and his coworkers, using inoculum provided by this laboratory, have induced disease in chimpanzees inoculated intramuscularly only with a single injection of kuru-infected chimpanzee brain tissue. Incubation periods for both animals were within the range we have previously reported (personal communications).

No matter what the route of inoculation has been thus far, or whether the virus has originated from infected brain or infected visceral tissue, or indeed, if the virus suspension was prepared from fresh tissue or had been lyophylized, exposed to heat, or clarified by $220 \mathrm{~nm}$ filtration or centrifugal sedimentation and resuspension, the resulting clinical disease and histopathological lesions remain remarkably unchanged and reproducible.

Extensive search for an antibody to the virus in man or experimental animals has failed. There is no detectable neutralizing antibody in human or animal sera at any stage of disease, or in sera from animals vaccinated with multiple injections of kuruinfected human and animal tissues, including brain. No demonstration in vitro of an antibody by complement-fixation or immunofluorescent techniques has been successful, and attempts at the precipitation of virus as a virus antibody complex with "immune" sera and antigammaglobulin have failed. No gammaglobulin or complement deposits or virus-antibody complexes have been demonstrable in serum or in frozen sections of brain, kidney, or other tissues. Wide screening for antibodies in the sera of kuru patients and of animals affected with experimental kuru has failed to reveal any significant or consistent pattern of reaction that would indicate an antigenic relationship to any one or combination of over 50 virus antigens tested.

\section{Transmissible Pre-senile Dementia}

The successful transmission of kuru from man to subhuman primates provided the stimulus and 

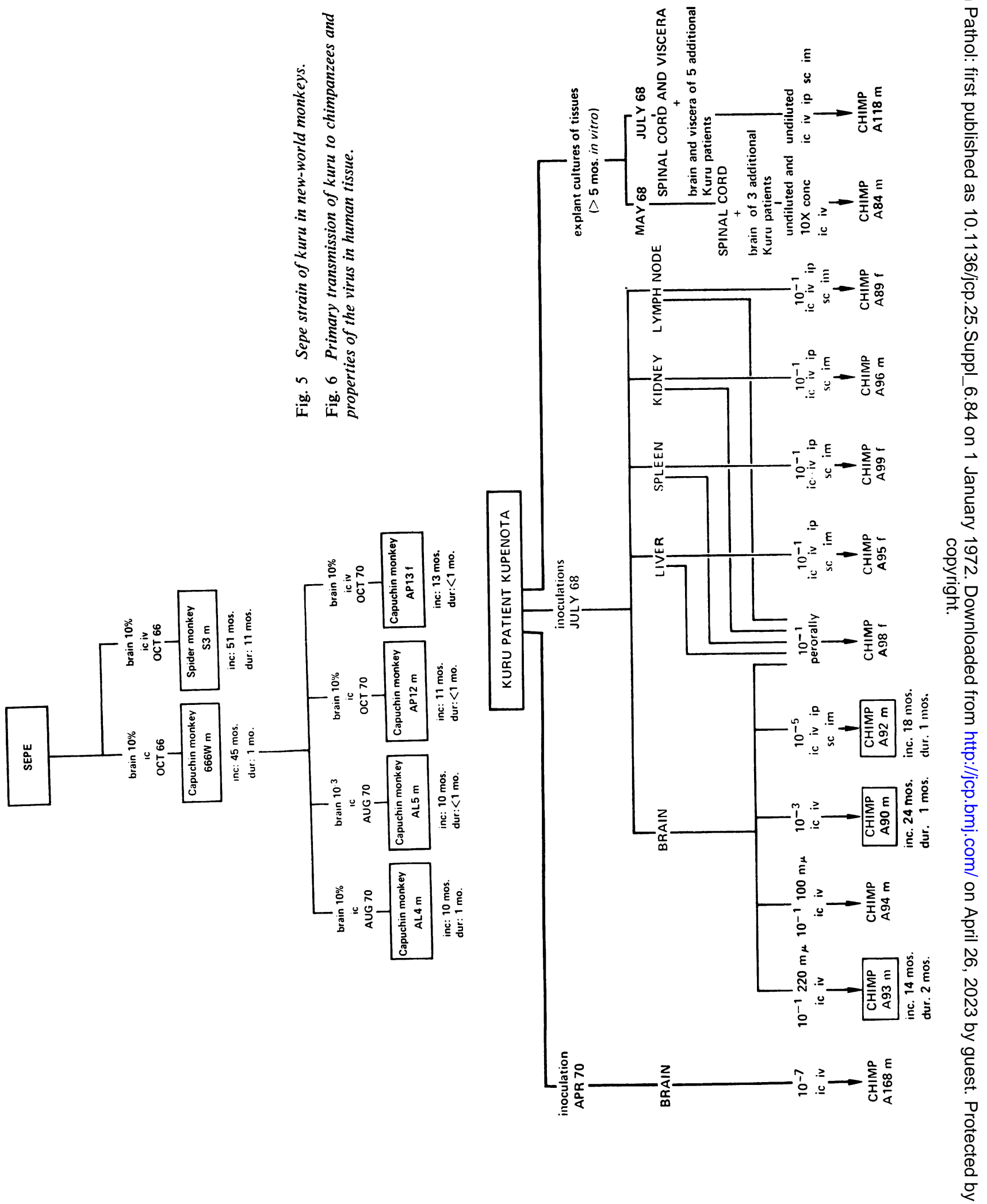

Clarence J. Gibbs Jr and D. Carleron Gajdusek

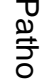

$\stackrel{\vec{F}}{\stackrel{\vec{S}}{+}}$

뭉

ڤ

$\vec{\circ}$

$\overrightarrow{\vec{\omega}}$

ㅇํㅇ

Uั

$\frac{\text { C }}{\frac{0}{0}}$

穴

으 


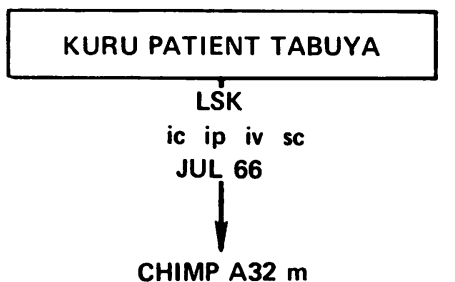

CHIMP A32 m
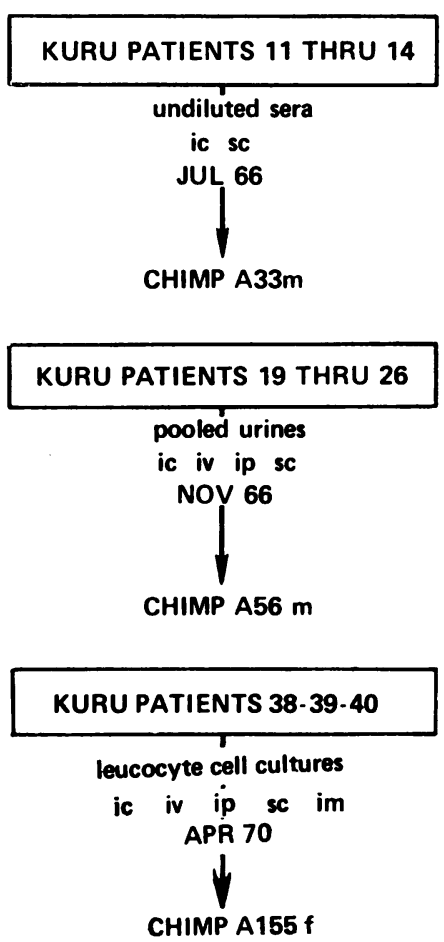

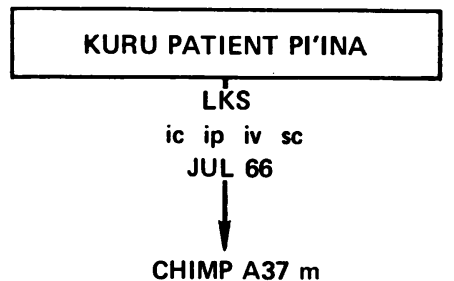

CHIMP A37 m
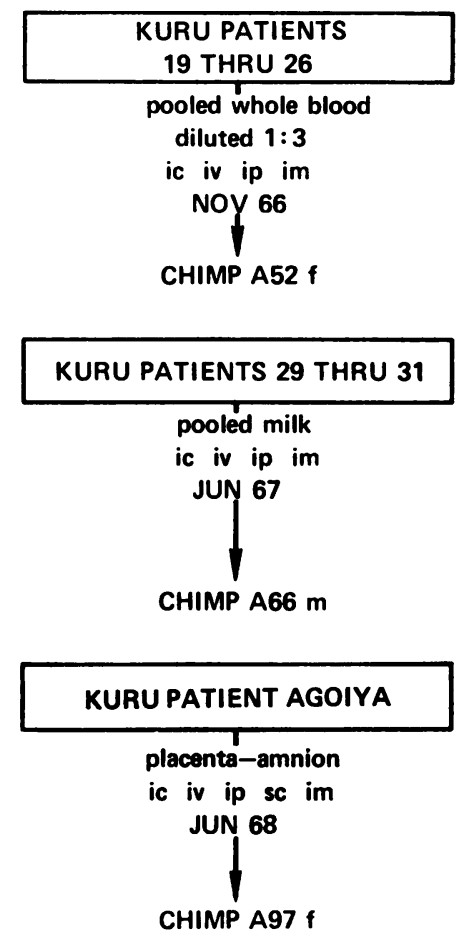

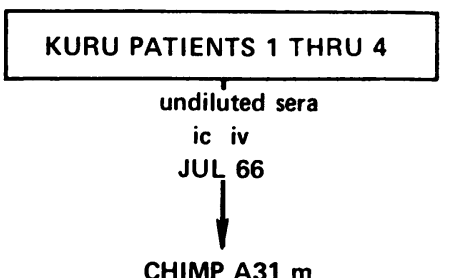

KURU PATIENTS 32-33-34

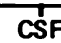

undiluted

ic iv im sc

AUG 67

CHIMP A69 m

KURU PATIENTS EPI \& ASOGU

KŚN

ic iv im sc

JUL 67

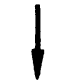

CHIMP A63 f

(died 5 mos.)

(pneumonia)

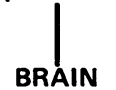

ic iv ip im sc

AUG 68

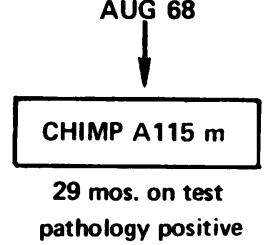

Fig. 7 Pathogenesis studies in chimpanzees to determine the distribution of kuru virus in human victims.

necessary techniques for the demonstration of a viral aetiology for the presenile dementia CreutzfeldtJakob disease. Indeed, efforts to demonstrate infection as the aetiology of Creutzfeldt-Jakob disease were based entirely on the striking similarity in the neuropathological lesions observed in the brains of patients with kuru and the brains of patients with this disease (Klatzo, Gajdusek, and Zigas, 1959). The only variations seemed to be those of distribution and intensity of the lesions in the brains of patients dying with the two diseases.

We have now successfully transmitted CreutzfeldtJakob disease independently from 14 of the 26 human cases to 18 of the 42 chimpanzees inoculated Details on the primary transmissions of 12 of these cases to 14 chimpanzees are summarized in Figure 9. As may be noted, incubation periods have ranged from 11 to 16 months, which is considerably shorter than those on primary transmission of kuru. Like kuru, the disease can be induced in animals inoculated peripherally only without intracerebral inoculation but with a slightly longer incubation period of 16 months. The disease is serially transmissible in chimpanzees and is already in fourth serial passage (Fig. 10). The virus has also been successfully transmitted on primary passage to three species of new- 


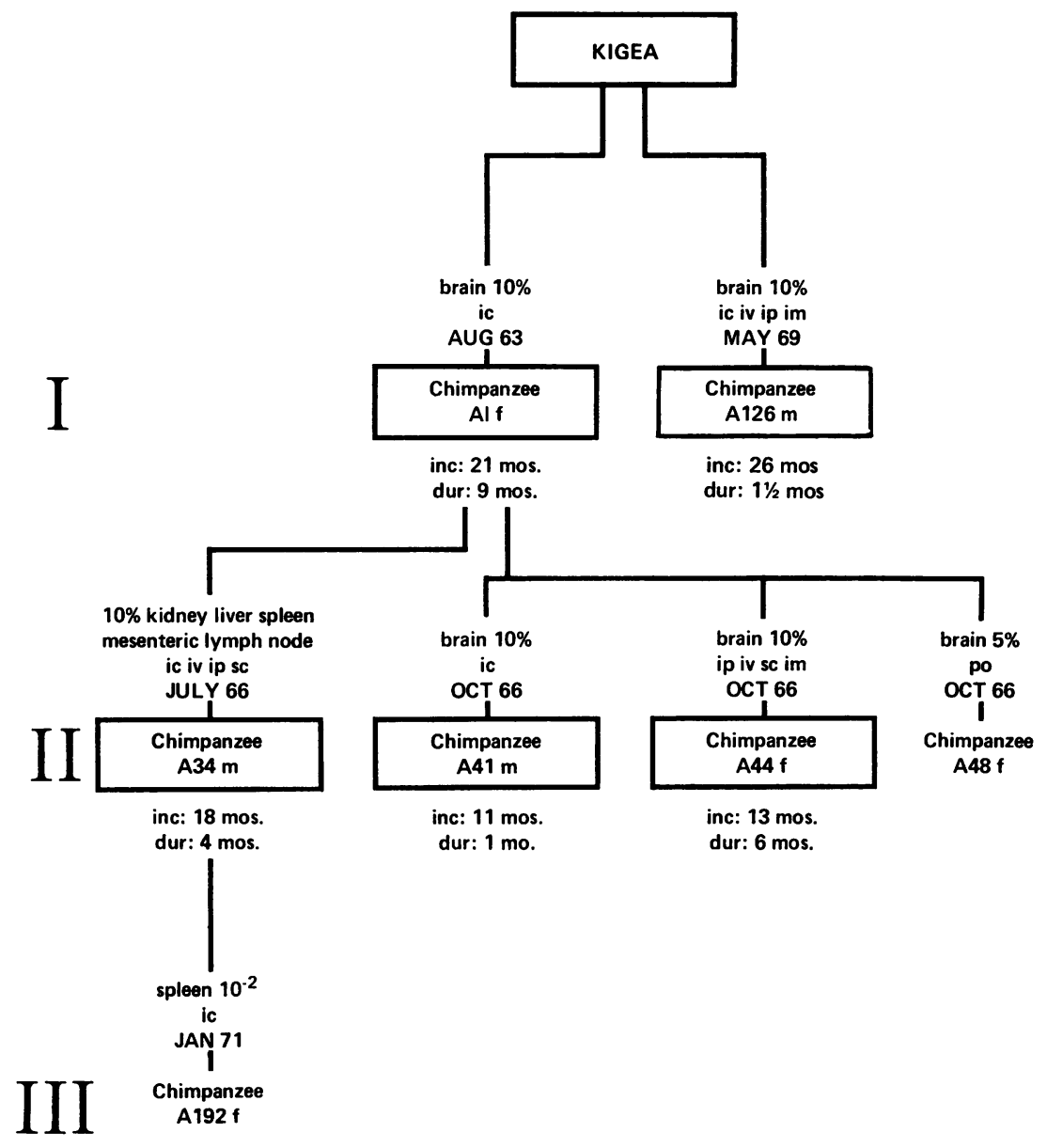

Fig. 8 Primary transmission and serial passage of kuru virus in chimpanzees by intracerebral inoculation of brain tissue or visceral tissues only, and by inoculation of brain tissue peripherally only. A126 was a fully mature aged chimpanzee.

world monkeys, ie, squirrel monkey, spider monkey, and capuchin monkey, after incubation periods of 24 to 27 months (Fig. 11) and on serial passage from chimpanzees to squirrel, spider, capuchin, and woolly monkeys with incubation periods ranging from nine to $28 \frac{1}{2}$ months (Figs. 12 and 13). The total number of cases successfully transmitted to chimpanzees or one or more species of new-world monkeys now stands at 19.

Like kuru the virus of Creutzfeldt-Jakob disease passes through a Millipore filter of $220 \mathrm{~nm}$, but has not yet been detected in the filtrates of smaller size Millipore filters. Nor has the virus yet been isolated from visceral tissues, whole blood, serum, cerebro- spinal fluids, or urine obtained from human patients or experimental animals affected with the disease. No specific antigen-antibody reaction has been demonstrated in patients or animals, a finding similar to that observed in our studies of kuru.

Both kuru and Creutzfeldt-Jakob disease infectious viruses persist in vitro in cultures of explanted animal and human tissues, respectively (Gajdusek, Gibbs, Rogers, Basnight, and Hooks, 1972). Kuru virus was found to persist in chimpanzee brain cells maintained in vitro at $37^{\circ} \mathrm{C}$ for at least 70 days and the virus of Creutzfeldt-Jakob disease persisted in human brain cells maintained in vitro at $37^{\circ} \mathrm{C}$ for at least 255 days. An attempt to demonstrate interfer- 

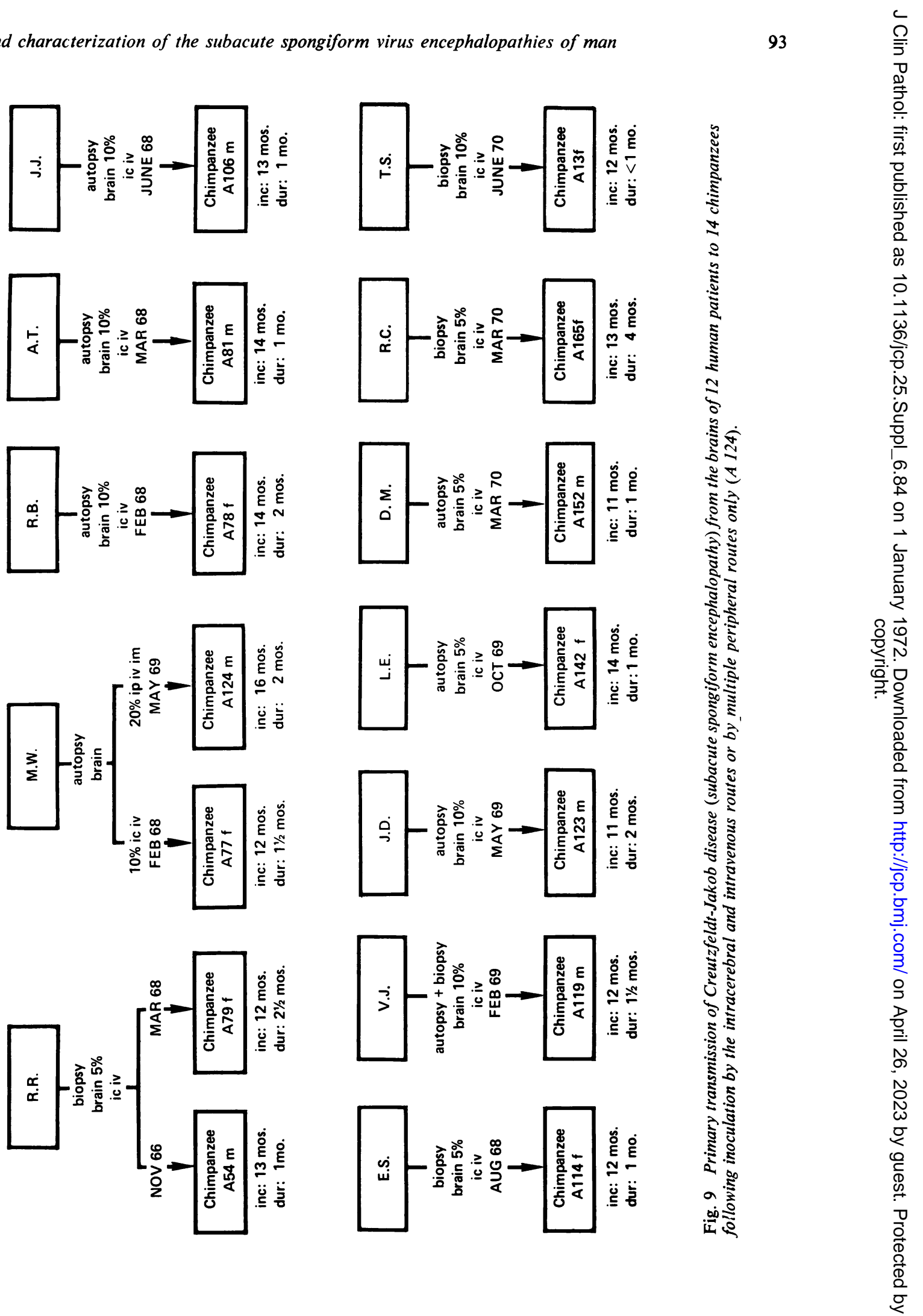


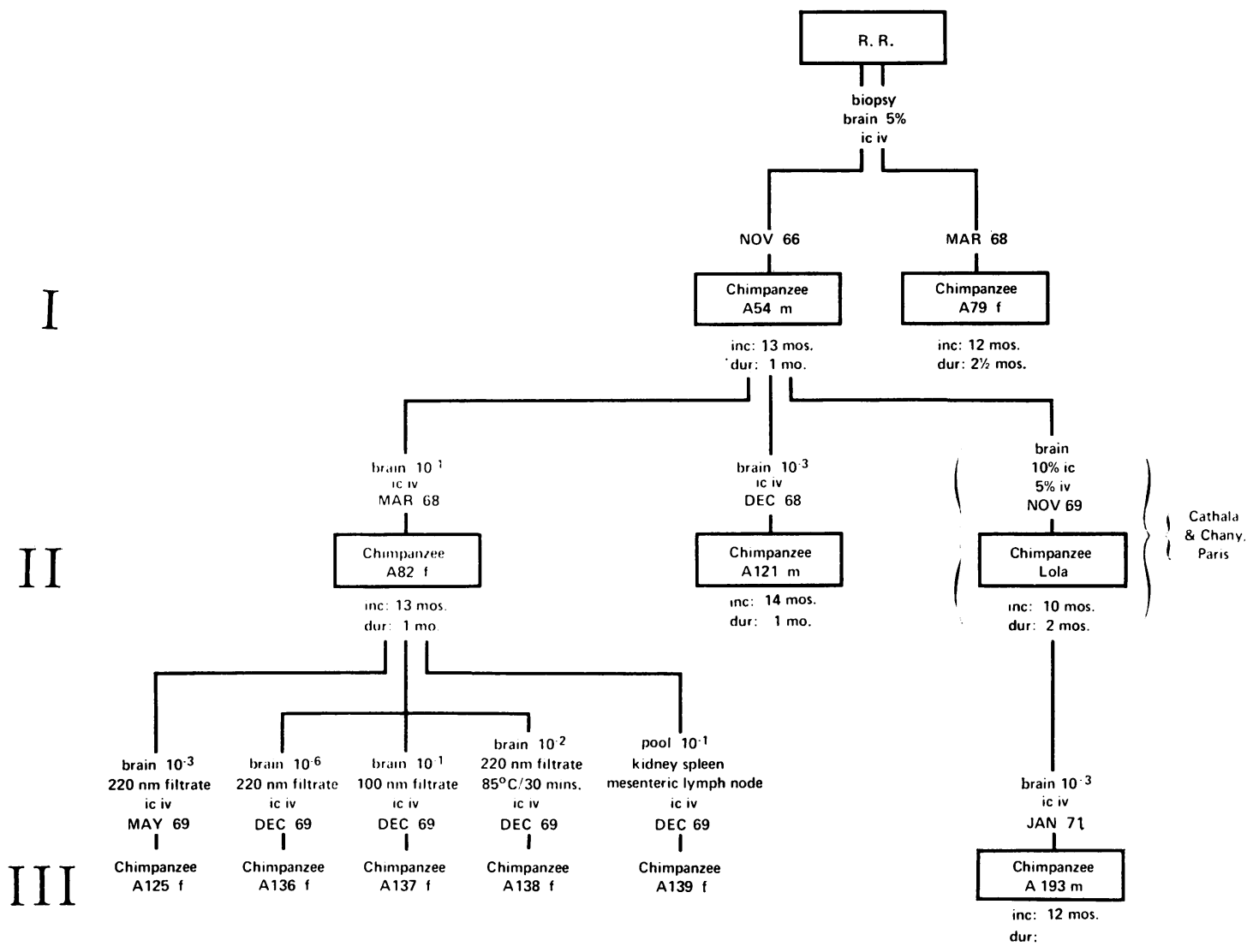

Fig. 10 Serial passage of Creutzfeldt-Jakob disease in chimpanzees and attempts to determine properties of the virus.

ence in these cultures using 14 different viruses has been unsuccessful (Cornelius and Gibbs, in preparation). Test viruses titred no differently in the cultures infected with virulent Creutzfeldt-Jakob and kuru virus than they did in normal chimpanzee brain cultures. Further, there was no evidence of interferon production in any of the infected brain cells. Treatment of kuru-affected chimpanzees with the interferon-inducing, double-stranded RNA polyinosinicpolycytidylic acid has no apparent effect on the clinical course of the disease (Gibbs and Gajdusek, unpublished data).

Finally, an extensive electron microscopic search for virus in infected tissues of man and animals, as well as in the fractions of brain suspension obtained by density gradient banding the agent in zonal ultracentrifuge, has revealed no recognizable virions
(Gibbs and Gajdusek, unpublished data; Siakotos, Gajdusek, Gibbs, and Traub, unpublished data; Lampert, Earle, Gibbs, and Gajdusek, 1970). However, although we can see no consistent evidence of fully formed mature virions certain of the degenerative processes seen must represent the effects of virus production and maturation. It thus becomes a challenge to evaluate which histological degenerative changes are primary effects of synthesis of virus components and virus assembly-incomplete and distorted though they may be-and which are secondary effects unrelated directly to virus, to synthesis of viral subunits, and virus assembly. However, even these secondary effects should eventually be relatable to metabolic interference caused by virus. Although fully formed mature virions may appear in tissue cultures or other cell 


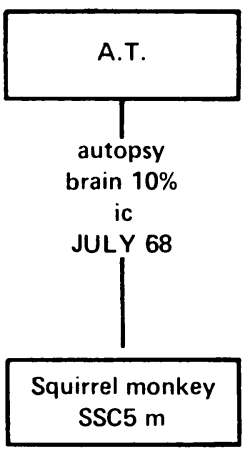

inc: 25 mos.

dur: $1 \frac{1}{2}$ mos.

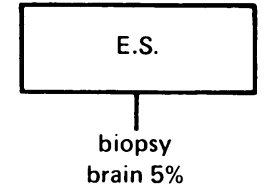

ic

AUG 68

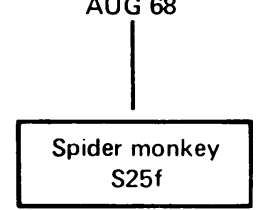

inc: 25 mos.

dur: $2 \frac{1}{2}$ mos.

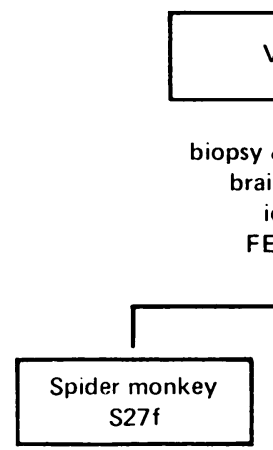

inc: 23 mos.

dur: $1 \mathrm{mo}$.

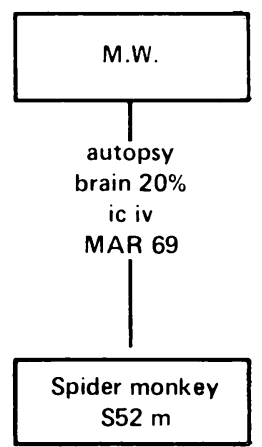

inc: 26 mos. dur: $>1 \mathrm{mo}$

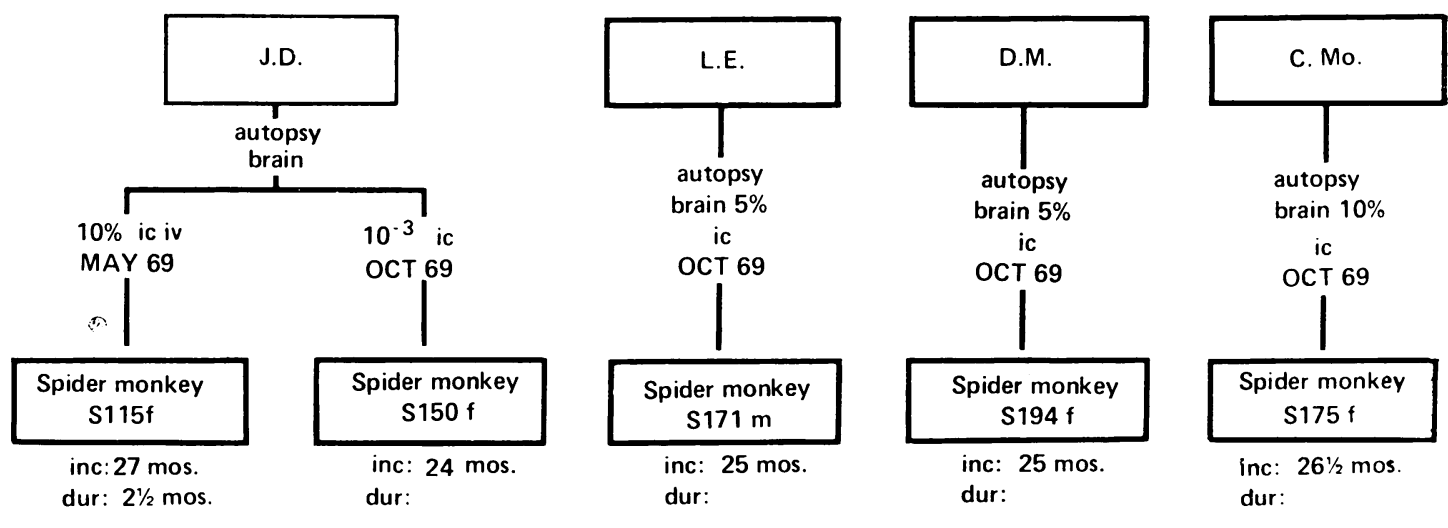

Fig. 11 Transmission of Creutzfeldt-Jakob disease from man to new-world monkeys.

systems, it should not be surprising to find asynchronous or unintegrated assembly stages leading to a typical incomplete or partial stage of virion synthesis.

\section{References}

Asher, D. M., Gajdusek, D. C., and Gibbs, C. J., Jr. (1972). Recent progress in the spongiform encephalopathies. Vestn. Akad. med. Nauk., in press.

Baublis, J. V., and Payne, F. E. (1968). Measles antigen and syncytium formation in brain cell cultures from subacute sclerosing panencephalitis (SSPE). Proc. Soc. exp. Biol. (N.Y.), 129, 593-597.

Carpenter, S., Karpati, G., and Wolfe, L. (1970). Virus-like filaments and phospholipid accumulations in skeleton muscle. Neurology (Minneap.), 20, 889-903.

Chou, S. M. (1967). Myxovirus-like structures in a case of human chronic polymyositis. Science, 158, 1453-1455.

Chou, S. M. (1968). Myxovirus-like structures and accompanying nuclear changes in chronic polymyositis. Arch. Path., 86, 649-658.

Chou, S. M., and Gutmann, L. (1970). Picornavirus-like crystals in subacute polymyositis. Neurology (Minneap.), 20, 205-213.

Cornelius, R., and Gibbs, C. J., Jr. (1972). In preparation.
Gajdusek, D. C.: (1963). Kuru. Trans, roy. Soc. trop. Med. Hyg., 57, 151-169.

Gajdusek, D. C. (1967). Discussion on kuru, scrapie and the experimental kuru-like syndrome in chimpanzees. In Curr. Top. Microbiol. Immunol., 40, 59-63.

Gajdusek, D. C., and Gibbs, C. J., Jr. (1971a). Transmission of two subacute spongiform encephalopathies of man (kuru and Creutzfeldt-Jakob disease) to New World monkeys. Nature (Lond.), 230, 588-591.

Gajdusek, D. C., and Gibbs, C. J., Jr. (1971b). Persistent, defective and slow virus infections of the nervous system of children. In Proceedings of the XIIIth International Congress of Pediatrics, III, Vienna, 1971, vol. 2, Neurology and Psychiatry. Vienna Academy of Medicine.

Gajdusek, D. C., and Gibbs, C. J., Jr. (1972). Nature (Lond.), in press. Gajdusek, D. C., Gibbs, C. J., Jr., and Alpers, M. (1966). Experimental transmission of a kuru-like syndrome to chimpanzees. Nature (Lond.), 209, 794-796.

Gajdusek, D. C., Gibbs, C. J., Jr., Asher, D. M., and David, E. (1968). Transmission of experimental kuru to the spider monkey (Ateles geoffreyi). Science, 162, 693-694.

Gajdusek, D. C., Gibbs, C. J., Jr., Rogers, N. G., Basnight, M., and Hooks, J. (1972). Persistence of viruses of kuru and CreutzfeldtJakob disease in tissue cultures of brain cells. Nature (Lond.), 235, 104-105.

Gajdusek, D. C., and Zigas, V. (1957). Degenerative disease of the central nervous system in New Guinea: the endemic occurrence 


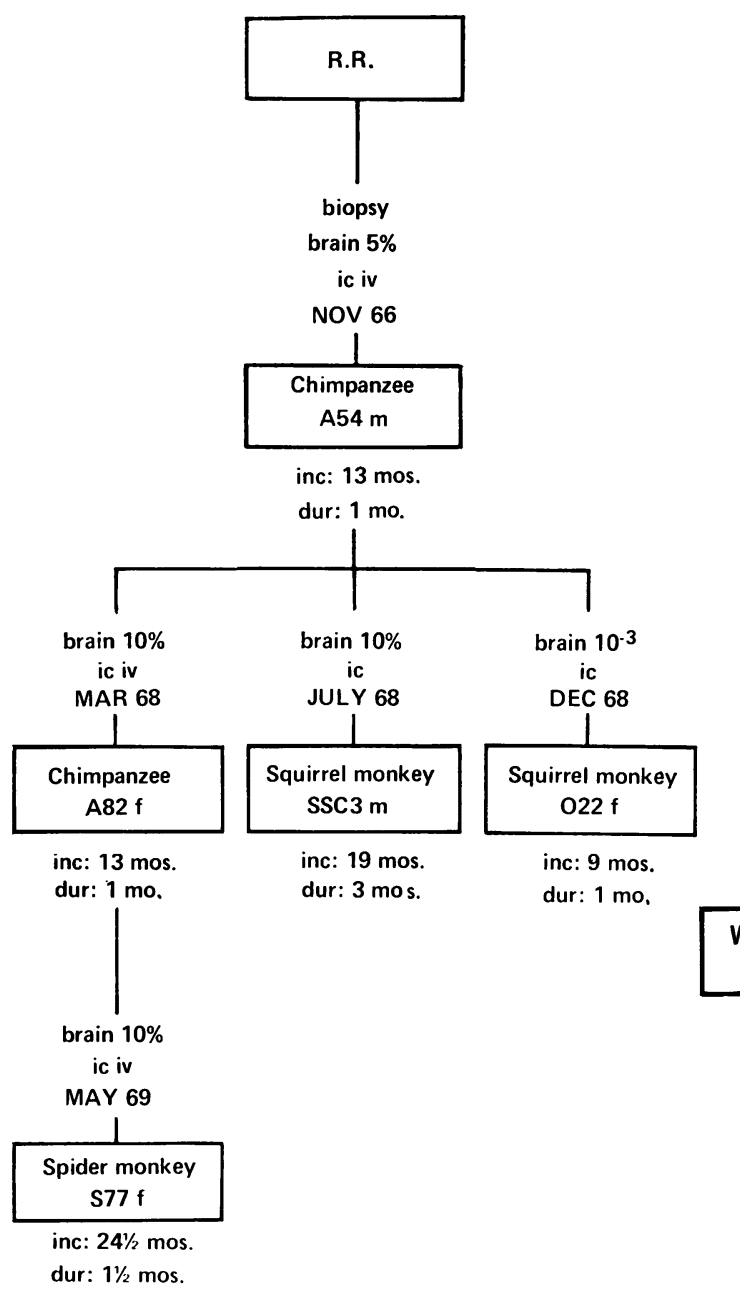

Fig. 12 R.R. strain of Creutzfeldt-Jakob disease in newworld monkeys.

of 'kuru' in the native population. New Engl. J. Med., 257, 974-978.

Gibbs, C. J., Jr., Alpers, M., and Gajdusek, D. C. (1969). Attempts to transmit subacute and chronic neurological diseases to animals. With a progress report on the experimental transmission of kuru. In Pathogenesis and Etiology of Demyelinating Diseases, edited by K. Burdzy and P. Kallós, pp. 519-552. Karger, Basle.

Gibbs, C. J., Jr., and Gajdusek, D. C. (1965). In Slow, Latent and Temperate Virus Infections, edited by D.C. Gajdusek, M. Alpers, and C. J. Gibbs, Jr., pp. 39-48. (NINDB Monographs, No. 2, PHS Publications No. 1378). National Institute of Neurological Diseases and Blindness, Washington, D.C.

Gibbs, C. J., Jr. and Gajdusek, D. C. (1970). Kuru in New Guinea: pathogenesis and characteristics of virus. Amer.J. trop. Med., 19, 138-145.

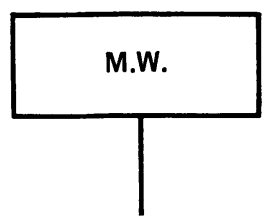

autopsy

brain $10 \%$

ic iv

FEB 68

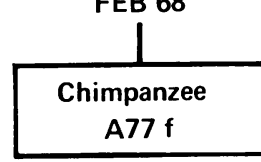

inc: 12 mos.

dur: $1 \frac{1}{2}$ mos.

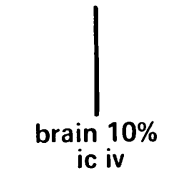

ic iv

MAR 69

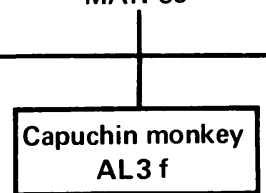

inc: $28 \frac{1}{2} \operatorname{mos}$.

inc: 21 mos.

dur: $5 \frac{1}{2}$ mos.

inc: $28 \frac{1}{2}$ mos.
Fig. 13 M.W. strain of Creutzfeldt-Jakob disease in newworld monkeys.

Gibbs, C. J., Jr., and Gajdusek, D. C. (1971). Virological studies of agents isolated from subacute and chronic neurological diseases. In Proceedings of the XIII International Congress of Pediatrics, Vienna, 1971, III/2, Neurology and Psychiatry. Vienna Academy of Medicine.

Gibbs, C. J., Jr., Gajdusek, D. C., Asher, D. M., Alpers, M. P., Beck, E., Daniel, P. M., and Matthews, W. B. (1968). CreutzfeldtJakob disease (subacute spongiform encephalopathy): transmission to the chimpanzee. Science, 161, 388-389.

Klatzo, I., Gajdusek, D. C., and Zigas, V. (1959). Pathology of kuru. Lab. Invest., 8, 799-847.

Lampert, P. W., Earle, K. M., Gibbs, C. J., Jr., and Gajdusek, D. C. (1970). Electron microscopic studies on experimental spongiform encephalopathies (kuru and Creutzfeldt-Jakob disease) in chimpanzees. In Proceedings of the VIth International Congress on Neuropathology, Paris, pp. 916-930. Masson, Paris. 